Article Type: Research Paper

\title{
The Motives of Sudanese Tourists to Choose Bandung as A Tourism Destination
}

\author{
Hussein Gibreel Musa ${ }^{1 *}$ and Ika Nurul Qamari ${ }^{2}$
}

\begin{abstract}
AFFILIATION:
${ }^{1}$ Student in Management Doctoral Program, Universitas Muhammadiyah Yogyakarta and lecturer in El Geneina University, Sudan.

2 Universitas Muhammadiyah Yogyakarta. Yogyakarta. Indonesia

\section{*CORRESPONDENCE:}

husseingibreel7@gmail.com
\end{abstract}

THIS ARTICLE IS AVALILABLE IN:

http://journal.umy.ac.id/index.php/mb

DOI: $10.18196 / \mathrm{mb} .11189$

\section{CITATION:}

Musa, H. G., \& Qamari, I. N. (2020). The Motives of Sudanese Tourists to Choose Bandung as a Tourism Destination. Jurnal Manajemen Bisnis, 11(1), 76-89.

Received: 2 March 2020

Accepted: 19 March 2020

\begin{abstract}
The motivation factor is one of the most important elements for choosing tourism destination, this study aims to find out the motives of Sudanese tourists for choosing Bandung as tourism destination, this research uses a Qualitative approach to describe this topic as phenomenological study, the study showed that the factor of culture, religion, behavior, nature, the experiences of former tourists, shopping, price, have a very big role in motive Sudanese tourists to choose Bandung as a tourist destination. This study shows that the factors of excellence tourist destinations in Bandung have important indicators including the type and nature of tourist attractions; service quality, physical and social environment, cost, accessibility, and behavior of local residents to tourists. Tourist destinations in Bandung in the view of some Sudanese tourists have high accessibility, leading tourist attractions in tourist destinations easily accessible because of good road conditions. In the regulation of traffic and transportation is very chaotic because the traffic rate of vehicles is so crowded. Decent accommodation and a complete and clear guide/instruction. The lowest score is the attribute of the accessibility of tourist destinations in Bandung.
\end{abstract}

Keywords: Tourist Motives; Tourism Business; Indonesian Tourism; Tourist Destination.

\section{Introduction}

Tourism is one of the mainstay sectors for Indonesia. This is evident that tourism has provided a very large contribution as a contributor to the country's foreign exchange (Irshad, 2010). Today various efforts are being made and have been pursued by the government together with the private sector to develop, preserve existing tourism, and continue to explore the potential that exists to be developed into a tourist attraction. Indonesian tourism if able to be packaged and managed properly will be an asset of the Indonesian State which can be able to compete internationally with tourism in other countries. Until now, tourism in Indonesia has not run optimally, even though this aspect is very influential on increasing people's income, especially local original income.

Indonesia as a country that has natural resources uses its wealth as an object to bring in foreign exchange through natural tourism. Thus it is hoped that tourism will develop well and have a good impact. Where 
in the end it is hoped that tourism can provide prosperity both economically and in terms of the standard of living of the community itself in general or tourism actors in particular. But siphoning visitors with a good promo is not always linear with what is in reality (Stoica, Orzan, Dobrescu, \& Radu, 2015). Tourism is not only built through promotion but also built by a tourism business system like a spider's web. Tourism as a complex business requires support from all sectors such as communities, travel tours, hotels and so on. The tourism business is essentially a complex business that involves many institutions, capital, and also government involvement. All have a share in building sustainable tourism.

The era of internet technology has made tourism business increase. With the internet, a lot of information is provided for travelers about certain tourist objects of interest (Ferguson, 2011). Medium internet makes it easy for tourists to get information related to travel.

Bandung is known as one of the leading tourist destinations in West Java Province, nationally, and even internationally. The development of Bandung tourism is supported by the availability and variety of urban tourism products in the form of various city features, both primary and secondary elements, such as knowledge, history, culture, heritage, culinary, shopping, and so forth. In line with the function of Bandung as the capital of the province of West Java and the city of services, MICE (Meeting, Incentive, Conference, Exhibition) tourism products, as well as educationbased tourism are also the main seeds.

The city of Bandung was crowned as the capital of Asia and Africa in April by 2015 AsianAfrican conference delegates. Bandung was chosen because it has a long history of inspiring countries on both continents to gain independence and recognition from the outside world. Bandung is not only known for its music, artistic creativity, and culinary tourism. Bandung is also known as one of the cities producing beautiful women with their own distinctiveness. Beauty is relative, but the fact is not excessive, because Bandung and almost all regions in West Java are known for their elegance, beauty, language friendliness, tenderness, and the special characteristics of the women.

Bandung is known as a region or area in the highlands surrounded by mountains, making it an area that has very cool temperatures, even in some parts of the region, such as in the natural tourist area of Lembang, still has a very cold air climate. tourists outside the area such as Sudan residents or their homes have hot temperatures, making Bandung one of the popular and favorite holiday destinations on year and especially when the holidays arrive just to refresh or spending honeymoon.

There are many tourist countries neighboring Sudan such as Egypt, South Africa, Morocco, etc.), but recently, Sudanese have preferred Bandung as a tourist destination to spend their honeymoon and vacations, so during this research, the researcher tries to study this phenomenon using the qualitative method to explore and describe the Sudanese tourists motivation and experiences for choosing Indonesia, 
Bandung particularly as main destination, the researcher conducted interviews with some Sudanese tourists, and use observation and recording as helping tools in data collection.

The motivation factor is one of the most important elements of psychology. Because the motivation of Sudanese tourists coming to Bandung destinations can be seen through the activities they do(Kotler, Bowen, Makens, \& Baloglu, 2017). So that it can be used as a reference for managing the development of facilities and infrastructure in a location tourist destination. This study aims to identify and determine tourism management policies in the future, so research is needed to examine the motivation and characteristics of Sudanese tourists who have visited Bandung.

\section{Literature Review}

The existence of the tourism industry, travel and hospitality is very dependent on social media in promoting its services. This is one that raises the motivation of tourists in finding the right tourist destinations to visit. As social media continues to surge in reach and influence, tourism providers cannot rely on traditional media (print, radio, television, etc.) at the moment to shape consumer perceptions about their products. Travelers use various social media forms as a tool to educate themselves about destinations and influence other tourists. Utilization of social media by tourists includes the whole trip, from pre-trip, in-trip to post-trip. Tourism marketers will be able to develop strategies around social media if they better understand the motives behind the use of social media during each phase of the tourist life cycle (Joseph, A. I., \& Kumar, S. V. A., 2016).

Fodness (1994) believes that tourist motivation is the driving force behind one's behavior in setting tourist destinations. Although there are extraordinary factors that influence tourist behavior, motivation is still an important indicator and force to answer why tourists behave in certain ways in enjoying tourism.

This literature review section aims to have a better understanding of the motivations and motivations of tourists, and try to examine how the motivation/motives of tourists in setting tourist destinations. Motivation is a process whereby needs, preferences, desires and expectations influence people's behavior (Kay, 2009). Motivation can be illustrated as the process and driving force that causes behavior and is controlled by the needs and desires of the person himself.

Motives are part of the motivation process. Compared to motivation, motives are easier to measure because they are not sustainable and change (Bansal, H., \& Eiselt, H. A., 2004). Tourist motives are a combination of demands and desires that influence people to travel in a general sense (Barber, N. A., 2014). Scholars sometimes argue differently about the predictive power of motives on intentions and behavior.

Because it could be someone motivated by different motives but have the intention to go to the same destination, or do the same behavior. Besides that, motives do not come 
as singular, usually several motives are united and produce influence on people's intentions and behavior. It makes sense to talk about the main and supporting motives for a trip, and travel is a way to make sure all motives are met or at least partially satisfied so that no one is debating how powerful a motive is in explaining people's intentions.

Tourism (as a service business phenomenon) is highly dependent on the advancement of communication and transportation technology, which is strengthened by the movement of money and distribution of companies (for example: different airlines and transportation companies, hotel chains, catering and logistics... etc). Exogenous factors and markets have an important role in shaping the development of tourism. Exogenous factors such as demographic and social change, economic and financial development, infrastructure and transportation growth, technology development and development in trade, are very important contributors to the growth of tourism as an industry (Mustafa, M. H., 2010).

As an industry that has market power, visible developments in products, marketing, computer reservation systems, global destination databases, and operator products, all lead to variations in the tourism market and choices offered to tourists around the world. Therefore it is logical to consider tourism as a major component in the globalization process. In addition, an indicator of the growth of the tourism industry is characterized by receipts and the flow of travelers that stretch across the world, increasing markets (groups of tourists), the speed of entry of different destinations into the development of tourism, increasing vacation destinations and the distance between them; all reflect the advances supported by technology and telecommunications, finance, and transportation, which play an important role in tourism globalization.

Tourism business is any activity that provides products and services for tourists with various facilities needed. The tourism business will involve the tourism industry, the travel industry and the hospitality industry, where each industry will contribute to the results felt by tourists. There are several driving forces of globalization that have a clear impact on the tourism, travel and hospitality industries. The liberalization of air transportation, the liberalization of trade in services, and the dissemination of information and communication technology, the widespread use of the internet in the sale and marketing of travel and tourism packages, all contribute to the growth of a sustainable tourism industry (Musa, Mulyana, Bajari, \& Navarro, 2020). The 21st century global travel and tourism industry is largely dependent on civil aviation, this can be seen clearly through national government policies and international and regional industrial organizations to improve coordination between air transportation, airport infrastructure, tourism investment and tourism development policies.

The increase will increase the contribution of the travel and tourism industry to the national economy and regional development, developed and developing countries are highly dependent on tourism as the main source of wealth and employment opportunities, and who seek foreign investment to exploit and manage 
them better. Natural resources, landscapes, history or culture for tourism purposes, are now at the forefront to encourage the liberalization of air transportation. In addition, electronic technology also facilitates this growth by providing access to tariff and hotel information and online reservation services. In addition, there is the uniqueness of developing countries that can attract the motivation of tourists around the world.

\section{Research Method}

This research uses a constructivist paradigm with a qualitative approach and phenomenological study. The object of research is Sudanese tourists who visiting Bandung destinations. Not only visiting Bandung but these tourists some of them have also visited some tourism objects in Indonesia. The method of data collection is done by observing directly in research location to get a clear picture and data about the problems studied in Bandung tourist destinations. In addition, by conducting interviews with questions and answers directly by the informants, where later these data will be written in the form of quotations that describe the phenomon of research.

In this study the researcher used interviews as one way to collect data. The interview technique is to use a type of semi-open interview, which is an interview that is flexible but still within the specified method. Interview is an interaction in which there is an exchange / sharing of rules, responsibilities, feelings, beliefs, motives, and information.

The purpose of the interview is to obtain factual information which will be correlated with observations and written data as a supplement.

As discussed above, the location of the study was conducted in Bandung. The choice of location is because Bandung is one of the popular tourist destinations in Indonesia. Many foreign tourists who choose Bandung as one of the tourist stopovers while touring in Indonesia, also the researcher who living in Bandung has been sawing the phenomenon in tourism destinations.

The question in this study what are the motives of sudanese tourists for traveling to indonesia, particularly Bandung, how their perception about indonesian tourism.

\section{Result and Discussion}

\section{The factor of escape from the environment}

Many Sudanese tourists suffer from a hard and repeated work, and one of them feels that there is nothing new in his life. They find themselves in a state of boredom and discomfort because of the daily routine and the murderer, so they think of getting rid of this routine in a way of life For a temporary period, some may find the routine killer at home, he should start from home or work and should be the starting point is the point of routine in your life so he will decide to travel accompanied by some members 
of the family to get rid of this boredom.

Tourism can offer an escape from traditional social roles and the liberty to spend one's time however one chooses (Toelkes, 2018). Indeed, tourism reflects the "anti-structure" of life, an escape from something they mean to escape from the routine life in Sudan, rather than a quest for something. The travel motives originate from a lack of things needed for survival: a person can feel strongly that he is lacking something and cannot continue without satisfying it, like seeing new places and learning new things in Bandung. In tourism terms, this may sound harsh, but the fact is that for many a holiday is seen as a necessity for survival and to be elsewhere is seen as the only solution. The primary travel motive is wanting to escape from it all temporarily, leaving the home scene behind without being very much worried about where to go preferably to an environment more agreeable than the daily grind(Pan, Santos, \& Kim, 2017).

"After looking for tourist destinations that could help me get rid of boredom and routine, I found that there are many natural landscapes and tourist activities that distinguish Indonesia from others, so I chose Bandung as a tourist destination because it is very quiet and has good people."

From their point of view, This life need change And the positive in his life, the stages that pass on the human are just stations should not lengthen them, it is the happy person that makes everything goes according to what he wants, when you find someone neglected in his day and does not care about planning is itself with the days becomes boring and routine, It is nice to be at the university and sit with your friends and live today, but there is a point of the goal of the university is to complete the study and not negligent, live your life as you want according to the criteria of your goals do not make life take you wherever you go, but take life wherever you go.

"Search for simple things: Many of us think changing the routine is by changing work or raising money or looking for a job. These things may exist in our lives but do not make them the basis of happiness for you. It is good to have someone who is diligent in his work but finds time for fun when you sit with your parents, this happiness may be deprived of a lot or you have friends and brothers you need in a time of need. These things do not exist in others, look for things. Available to you and others if you think about it a little, you will find that you are in the grace of Allah grace but you do not feel it. You are not one of the people who does not know grace except if they lose it."

"Think about your life and you will find many things that you find joyful and need. You change its look. Change things: You may live in a room and have not changed its shape and the furniture it has for years. When you change from the room you live in, you have spent something that you may feel over time that you have broken a routine, bought new clothes or played and mixed with friends and family. You are the changer for yourself and do not wait for anyone to change your mood, make your mood suitable for any circumstances and any change in your life and promise to indulge in the things of the past and grief, and always look for new and enjoyable at work and study and home, not even a simple thing to feel happy and be happy no matter how hard life." 
As a result of these principles, they seek to change their daily lifestyle and travel to discover new areas and self-entertainment, because of this change, although simple, will positively affect our performance after the return. We will become more energetic and energetic and we may gain new experiences that can help us. At work, because the enjoyment of natural landscapes and picturesque is missing a lot of Arab countries and not only Sudan, and characterized by Indonesia from other countries.

Travel is a unique opportunity to change the routine lifestyle that one often experiences, allowing him to learn about different cultures and make new friends, in addition to having to rely on himself in all aspects of his life, especially if traveling alone (Croy, 2010).

The traveler can overcome many of his fears, such as fear of the highlands by confronting these fears and making a trip to the mountains, or visit tall towers.

"We may feel that we are living a happy and peaceful life in our surroundings, but this quiet life can sometimes become a tedious and tedious routine even if it is comfortable that what I felt in Sudan. So sometimes we need to get out of the crucible of this life for a while and go on a new adventure."

Travel may be the perfect experience that can change your life and break your routine for some time to come back again and relax.

Routine is fatal and affects us a lot negatively. So, we have to find a way to break this routine, at least once a year by traveling and testing new things out of the ordinary. Travel is also a great opportunity to relax and relax away from everyday stress.

One of the reasons for the escape is the permanent environment and the daily routine of the person, we feel that we repeat the work and the act and the whole day in the same image and actions every day, and feel the human recurrence of the day without adding to the day, even if something is simple, and get accustomed to the routine result from many factors Such as continuous work in a single environment or a long and deadly void or by doing things that a person does not like or living in a place where the person cannot rest, there must be things and breaks between the days of human life to give more and new and break the boredom by traveling or adding something new In the life of man or take a gift And leave or take a walk, man by nature needs to break this routine and be on his way and hand.

It gives the person a state of relaxation and enjoys the distance from the bushes and pressures and routine life; watching the beautiful natural places changes the human condition and the purity of his mind.

\section{Cultural factor}

The impact of rapid development in the world of communications and the spread of globalization throughout the world has the pros and cons of knowing the details of peoples, including their customs and traditions, wearing them, their food to another, and 
this has become a key factor in pushing people to travel and knowledge of these cultures closely (Blanchard \& Higgins-Desbiolles, 2013).

Indonesia is one of Southeast Asia's most heavily cultural countries, both from prehistoric times, Hinduism, Buddhism, Islam, and colonial times, scattered throughout the archipelago.

Countries such as Indonesia need hundreds of visits to learn about the culture of their tribes and peoples, because they are multi-religious, customs and traditions. Each tribe has a culture that is different from the other (music, dress, food, language, customs, etc.). Which drives the Sudanese people to choose Indonesia as a tourist destination, especially the city of Bandung because it is a cultural center with tribal, religious and cultural diversity, and one of the most modern cities in Indonesia in terms of architecture and planning, similar to European cities.

Tourist experiences can play a big role in creating a dialogue between different peoples, narrowing the gap between different cultures and cultures and creating conditions for the creation of a common universal language, the language of love and tolerance. Peace ... Perhaps the most important tools of communication are trips and embassies and their role in bringing the views of individuals, peoples and nations closer.

The tendency of man to the curiosity of knowledge, understanding of the other and the desire to control the outside world, has pushed him since the earliest times to move and communicate with other peoples and tribes, so he rushed from his territory to the neighbouring regions to discover their horizons and study the habits and customs of other peoples and tribes to conceal their secrets and converge with others In a respectful way in the search for security, because knowledge and culture can only know growth and prosperity in a climate of peace and affection.

The scientific value of the trips lies in the fact that they contain many knowledge and blogs that relate to geography and history in the strongest possible way. They contain detailed photographs and reports on the economic, social, political and architectural conditions of the Indonesians and other peoples, such as the knowledge of the monuments around the city of Bandung. And the country's historical relations with other countries, and to take a close look at the Asia-Africa Conference in 1955.

Hospitality and friendliness of people act as significant pull factors for both first times and repeat tourists, which is indicative of the need for esteem from others (Horng \& Tsai, 2010). Two sub-themes can be identified for this motive. The first was 'interactions with hotel employees. Tourists across nationalities mentioned that the 'smile', 'willingness to help', and 'warmth of welcome' of hotel employees and/or of the general population, accentuated by 'ease of communication with' and 'understanding by locals', led to the choice of the Bandung. Also, the advice and accommodation provided by tourism actors and friends tend to reinforce these perceptions of 'friendliness' (Crooks, Turner, Snyder, Johnston, \& Kingsbury, 2011). So the main factors push Sudanese tourists are: 
1. Go outside your city or even outside your country and learn about other people's lifestyles, because this is the best way to learn about other cultures. However, it cannot be said that all travel experiences lead to the recognition of other cultures. The best way to learn about Indonesia's culture is to work in the field of volunteerism, which often puts you at work and allows you to identify indigenous people in those areas you have visited and participate in. On pre-planned sightseeing trips that can provide you with the experience of living with the locals and the more you stay in one place for more, the more you admire and appreciate the culture of that place.

2. Before reaching your destination, try to read about the culture of the place you are looking for. If you visit a country and you do not have enough information about it, it will create many problems because you will be more affected by the cultural shock of that country and you will not be able to accept its culture You can easily get the information you need through the Internet, social media or reading a book so you can start your journey better and more comfortable but you should prepare yourself for a small cultural shock but do not worry, the information you got earlier will help you To overcome this small shock.

"From my experiences I can say there may be no problem wearing a Jalbia, hijab in a country like Indonesia but wearing it in some countries may be banned. Here ladies should especially pay attention to these important points about dress and welcome. if she/she learned some words from the Indonesian language, it can be interesting, convenient and simple for any cultural experience because most of the population does not speak English."

3. Make you immersed in the culture of Sunda to get to know it more. The best way to understand cultural differences is to see yourself as part of these differences. You should help the host to cook, participate in local events, get to know other people and use public transport. In that culture, the better you learn and grow your ideas, the more you have to communicate with a few people wherever you are and you will be surprised to see people's passion for you. Here you must say that you should not try to impose your culture on others.

4. Remember that you will get a cultural shock when you arrive for the first time in Indonesia. This shock will take a few days and the cultural shock is a disturbance and anxiety arising from being in a new place or culture. Even those with great travel experience are suffering from this kind of trauma but good news. Here, is that this shock quickly disappears and the best way to get rid of it, is to try to deal with it and communicate with the surrounding community because people in a smile are characterized by a smile and acceptance of the other. It is normal to be concerned when you are in a new place, but the best way to deal with this concern is to continue learning and face difficulties.

5. Share your cultural habits with others to encourage them to share their cultural habits and carry pictures of your personal life. The best thing you can carry while you travel. By doing so, others will learn about your life and culture. No matter where you come 


\author{
Musa \& Qamari \\ The Motives of Sudanese Tourists to Choose Bandung as A Tourism Destination
}

from, your life with others can be useful for you to learn about the culture and way of life of others and ultimately learning is the key to understanding and accepting issues.

\title{
Climate factor
}

Climate change is one of the world's greatest challenges because of its negative impact on various facilities and human dimensions. Tourism is one of the economic sectors most sensitive to the potential impacts of climate change, such as agriculture, environment, and water. The tourism sector in Indonesia is closely related to the landscape, environmental features and cultural characteristics of the region, directly or indirectly, these climatic features has led Indonesia to become one of the favorite destinations for Sudanese tourists recently, and will become a competitive global destination soon.

"Because of the mild climate and cold weather, I chose Indonesia, Bandung as a tourist destination, because life in Sudan is harsh under the very hot weather, I start feeling uncomfortable and depressed from the surrounding environment. My friend asked me to travel to Bandung for two weeks, and it was a rich experience."

Before choosing Indonesia, Bandung City as a holiday destination for leisure time or honeymoon, the first thing tourist should check out is the local weather for your destination. Because you are a runaway tourist in hot weather in Sudan, so it is very important to do some research on it, to make sure that the weather will be suitable for you. Traveling to Indonesia is the perfect choice for indulging in the many wonders of the country. As one of the world's most famous cities for landscape and cultural wonders, Bandung City is one of Indonesia's favorite tourist destinations. The weather in this city is very suitable for leisure and pleasure almost throughout the year.

"I encouraged Sudanese tourists to Bandung for vacation, especially for individuals living in communities characterized by a harsh climate in some months of the year like Sudan, where travel becomes desirable, allowing the traveler, along with recreation and psychological comfort through various activities offered by the other country, to know The manifestations of life in other societies from multiple angles."

In Africa, most tourists who go there are looking for sunbathing and tourist culture. Therefore, Sudanese tourists travel to Indonesia, especially Bandung, in search of a calm, warm or cool climate to spend nice and memorable moments that they will miss it there. The tourist should know the weather potential at his next destination, because this step will force him to choose the quality of his clothes in traveling and also choose the tourist activities scheduled for him there, but often the city of Bandung has a mild weather during the day, and cool at night, so the Sudanese tourist may not have trouble adapting to The weather here, in fact, may get some colds.

Factor Status and Dignity

The esteem needs show an individual desire for a feeling of self-confidence and adequacy. This may reflect internal feelings of strength, achievement, independence, or external 
desires of reputation, prestige, recognition, attention, so it is necessary to show the economic status in front of others to make them know the value of the tourist, and spread a good reputation about him, because it is a distinction in the choice of tourist destination, especially when it's related to honeymoon issue, where there is competition among friends about the tourist destinations that they will go to it to spend their honeymoon.

Even if all these needs are satisfied, we may still often expect that a new discontent and restlessness will soon develop, unless the individual has an inward vocation. In other words, what a man can be, he must be. These needs called self-actualization.

"It is important to mention the role of society in the process of identification since we constantly strive to define ourselves in relations to the world in which we live. To put it in other words, we gain a sense of which we are based not only on how we see ourselves, but also on how others see us. Identity, therefore, is not a static phenomenon, but continually negotiated and subjective to societal and situational contexts."

The preservation of reputations or the beautiful image in other people eyes has resulted from the competitive culture of Sudanese society. Every family compares itself with other family and looks to become like them. This kind of concept is born, so people focus on it too much and they take care to show good reputations and reflect the ideal image. To keep other people silent, by show off that they are special or Unique, sometimes this things costs them more than their ability, now many of the grooms start thinking too much about honeymoon trip to do show off, so why we see some Sudanese tourists travel to Bandung for honeymoon as we know there many options close to their country.

"I traveled to Bandung to show others that I was special because some members of my family suggested me to spend my honeymoon in Sudan but I refused because my values will diminish among my friends and surrounding society."

Referring to the discussion about Sudanese tourist's motivation factors for choosing Bandung as a destination, then it can be modeled as follows:
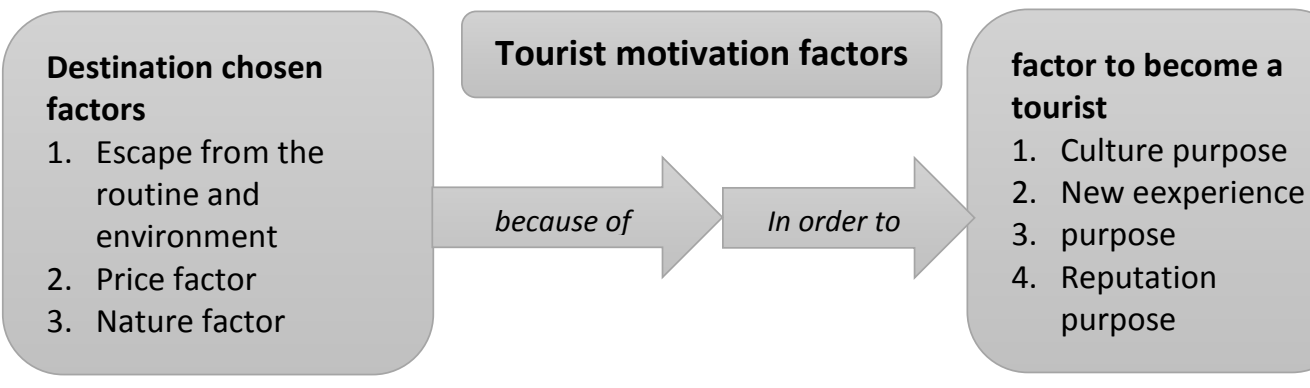

Figure 1 Model of motivation factors

Source: results and discussion data (2019)

Caption:

: The connection between elements each other

: The continuous process and connection 
The motivation factors model above shows that most of the Sudanese tourists they felt boring before travel because they are in a routine condition. There is nothing new, and the Sudanese environment was also a major reason because life is harsh so they are facing hot weather every day and people living daily life, anything like yesterday there is no change, so why a routine became one of the reasons that make them thinking about travel.

Also, one of the driving reasons for tourists to choose Bandung as a tourist destination is the price factor, because tourism in Indonesia in general and Bandung particularly are still cheap compared with other destinations such as Turkey, Malaysia, and others. The Sudanese tourists have prior knowledge that Bandung has amazing nature and beautiful tourist destinations. And the cool weather, all these features have become a factor for the Sudanese tourists to choose Bandung as a tourist destination.

As we know that behind each journey there is a hidden purpose traveler seek to achieve. One of the motives and objectives of the Sudanese tourists from their trip to Bandung is the cultural factor because tourists want to communicate with people to know Indonesian culture closely because they know that Indonesia is rich with cultural diversity.

The Sudanese tourists also seek to get new and unique experience because this environment is different from their homeland, also one of purpose to maintain their reputation and status among the community because of the majority of Sudanese boast about traveling abroad.

\section{Conclusion}

In making a trip, there are several factors that can affect the decision-making process of Sudanese tourists when he wants to choose a destination, in this study the factor of excellence of tourist destination and trip price are very decisive factors in the decision of Sudanese tourists to visit the attractions of Bandung. This can be seen from the result of interview and observation.

Based on the results obtained that the price factor has a calculated value and most important factor for Sudanese tourists for choosing Bandung as destinations for their leisure time, honeymoon, so the price factor has the strongest influence compared with other factors from Sudanese tourists perspective, then the price factor has a dominant influence on tourists satisfaction.

According to our results, the factor of excellence of tourist destination in Bandung has several indicators that are the type and nature of tourist attraction; service quality, physical and social environment, cost, accessibility, and behavior of local people to tourists.

The tourist destinations in Bandung are rated on average by some Sudanese tourists with high accessibility where the leading tourist spots in tourist destinations are easy to reach 


\section{Musa \& Qamari}

The Motives of Sudanese Tourists to Choose Bandung as A Tourism Destination

due to good road conditions except traffic, and there is a decent transport/accommodation and a complete guide/directions and clear. The lowest score in the accessibility attributes of tourist destinations in Bandung.

Among many factors reported playing a role of appealing elements for tourists' demand and when they want to choose destination, the food factor seemed to be less discussed, even though it is one of the main actors that can affect some tourists choices, because Sudanese tourists do not choose their destination based on the expected food.

\section{References}

Bansal, H., \& Eiselt, H. A. (2004). Exploratory research of tourist motivations and planning. Tourism management, 25(3), 387-396. https://doi.org/10.1016/s0261-5177(03)00135-3

Barber, N. A. (2014). Profiling the potential "green" hotel guest: Who are they and what do they want? Journal of Hospitality \& Tourism Research, 38(3), 361-387. https://doi.org/10.1177/1096348012451462

Blanchard, L.-a., \& Higgins-Desbiolles, F. (2013). Peace through tourism: promoting buman security through international citizenship: Routledge.

Crooks, V. A., Turner, L., Snyder, J., Johnston, R., \& Kingsbury, P. (2011). Promoting medical tourism to India: Messages, images, and the marketing of international patient travel. Social Science \& Medicine, 72(5), 726-732. https://doi.org/10.1016/j.socscimed.2010.12.022

Croy, W. G. (2010). Planning for film tourism: Active destination image management. Tourism and hospitality planning \& development, 7(1), 21-30. https:// doi.org/10.1080/14790530903522598

Ferguson, L. (2011). Promoting gender equality and empowering women? Tourism and the third Millennium Development Goal. Current Issues in Tourism, 14(3), 235-249. https://doi.org/10.1080/13683500.2011.555522

Fodness, D. (1994). Measuring tourist motivation. Annals of tourism research, 21(3), 555-581. https://doi.org/10.1016/0160-7383(94)90120-1

Horng, J.-S., \& Tsai, C.-T. S. (2010). Government websites for promoting East Asian culinary tourism: A cross-national analysis. Tourism management, 31(1), 74-85. https://doi.org/10.1016/i.tourman.2009.01.009

Irshad, H. (2010). Rural tourism-an overview. Rural Development Division, Government of Alberta, Canada.

Joseph, A. I., \& Kumar, S. V. A. (2016). Determinants of Social Media Use Across Tourist Lifecycle Phases-An Empirical Investigation of Tourist Motives. International Journal of Tourism and Travel, 9(1\&2), 1-7. Retrieved from https://www.cabdirect.org/cabdirect/abstract/20173085746

Kay, P. L. (2009). Cultural experience tourist motives dimensionality: A cross-cultural study. Journal of Hospitality Marketing \& Management, 18(4), 329-371. https://doi.org/10.1080/19368620802590217

Kotler, P., Bowen, J. T., Makens, J., \& Baloglu, S. (2017). Marketing for hospitality and tourism. Mulyana, Deddy. (2002). Metodologi Penelitian Kualitatif. Bandung. PT. Remaja Rosdakarya. Musa, H. G., Mulyana, D., Bajari, A., \& Navarro, C. J. S. (2020). Promoting tourism destinations through Sudanese tourists interacting experiences in Bandung. Jurnal Studi Komunikasi, 4(1), 21-31. https://doi.org/10.25139/jsk.v4i1.2150 


\section{Musa \& Qamari}

The Motives of Sudanese Tourists to Choose Bandung as A Tourism Destination

Mustafa, M. H. (2010). Tourism and globalization in the Arab world. International Journal of Business and Social Science, 1(1), 37-48. http://www.ijbssnet.com/journals/4.pdf

Pan, S., Santos, C., \& Kim, S. (2017). Promoting tourism, projecting power: The role of television commercials. Journal of Travel \& Tourism Marketing, 34(2), 192-208. https://doi.org/10.1080/10548408.2016.1156610

Richards, G. (2011), Creativity and tourism: the state of the art. Annals of Tourism Research, 38(4), 1225-1253. https://doi.org/10.1016/i.annals.2011.07.008

Stoica, I., Orzan, G., Dobrescu, A., \& Radu, A. C. (2015). Online Marketing Communication Using Websites. A Case Study of Website Utility in Accessing European Funds in the Tourism Field Regarding Northeastern Romania. Procedia Economics and Finance, 23, 926-935. https://doi.org/10.1016/s2212-5671(15)00436-0

Toelkes, C. (2018). Sustainability communication in tourism-A literature review. Tourism Management Perspectives, 27, 10-21. https://doi.org/10.1016/j.tmp.2018.04.002 